\title{
Health-related quality of life of patients diagnosed with COPD in Extremadura, Spain: results from an observational study
}

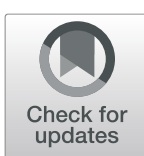

\author{
María Merino ${ }^{1 *}\left(\mathbb{D}\right.$, Renata Villoro ${ }^{1}$, Álvaro Hidalgo-Vega ${ }^{1,2}$, Concepción Carmona $^{3}$ and Collaborative Working Group
} EPOC-Extremadura

\begin{abstract}
Background: COPD is a high prevalence chronic disease that involves large reductions of health-related quality of life (HRQL) of patients. This study aims to describe the HRQL of patients with COPD in Extremadura (Spain).

Methods: This is a cross-sectional observational study carried out using a representative sample of patients diagnosed with COPD in Extremadura. The inclusion criteria were patients of legal age, diagnosed with COPD at least 12 months prior to the visit, residing in Extremadura, with electronic medical records available for the 12 months prior to the visit and providing informed consent. The intervention aimed to elicit HRQL indicators obtained from two validated questionnaires: EuroQol - 5 Dimensions - 5 Levels (EQ-5D-5L), and St. George's Respiratory Questionnaire-COPD (SGRQ-C). The main outcome measures were general HRQL (utility and visual analogue scale) and specific quality of life of COPD patients (total score and three component scores: Symptoms, Activity, and Impacts). Stepwise multiple regression analysis was applied to evaluate the association of EQ-5D-5L and SGRQ-C with respect to clinical and sociodemographic characteristics of the patients.

Results: We recruited 386 patients (mean age $71.8 \pm 10.3$ years, $76.2 \%$ males). In the EQ-5D-5L, participants reported greater problems with respect to mobility (56.5\%) and pain/discomfort (48.2\%). The mean utility was $0.72 \pm 0.31$, and the SGRQ-C total score was $40.9 \pm 25.0$. The results of both questionnaires were associated with number of exacerbations in the last 12 months, level of COPD severity, gender, and education level of the patient $(p<0.05)$.

Conclusions: The results for both utility and total SGRQ-C score indicate that having suffered exacerbations in the last year, presenting a higher level of severity, being a woman, and having a low education level are related to worse HRQL in patients with COPD.
\end{abstract}

Keywords: Obstructive pulmonary disease, Health-related quality of life, Primary care, EQ-5D-5L, SGRQ-C, Spain

\section{Background}

Chronic obstructive pulmonary disease (COPD) is characterized by an irreversible chronic airflow limitation mainly associated with smoking tobacco [1]. Although there are no recent data on its prevalence in adults in Spain, previous studies estimated the prevalence at approximately $4-10 \%$ [2-4]. However, these rates could have been underestimated in some cases, especially when based on the old criteria of the European Respiratory Society for defining COPD. Moreover, it is estimated that $73 \%$ of people with

\footnotetext{
* Correspondence: maria.merino@weber.org.es

${ }^{1}$ Fundación Weber, Calle Moreto 17, 5 D, 28014, Madrid, Spain

Full list of author information is available at the end of the article
}

COPD are not diagnosed [5]. According to the World Health Organization (WHO), more than 3 million people died in 2015 due to COPD [6], and COPD will be the third cause of death worldwide in 2030 [7]. In Spain, respiratory diseases were the third cause of death in 2015 following diseases of the circulatory system and tumours [8].

As with other highly prevalent chronic diseases, COPD involves an elevated cost, related both to consumption of healthcare resources and to a loss of health-related quality of life (HRQL) [9-13]. In fact, the interest in assessing the HRQL of patients with COPD as an endpoint in itself has grown in recent years [14]. In Spain, studies that estimate the HRQL of patients with COPD

(c) The Author(s). 2019 Open Access This article is distributed under the terms of the Creative Commons Attribution 4.0 International License (http://creativecommons.org/licenses/by/4.0/), which permits unrestricted use, distribution, and 
outside a hospital setting are scarce. To the best of our knowledge, this is the first study that assesses HRQL and its association with clinical and demographic variables, including COPD severity, using patientreported-outcome (PRO) measures from a representative sample of COPD patients in one of Spain's autonomous community (Extremadura). Validated PRO questionnaires provide a standardized method to assess the impact of the disease on patients' lives [15]. The use of a generic quality of life questionnaire such as the EuroQol-5 Dimensions-5 Levels (EQ-5D-5L), along with the St. George's Respiratory Questionnaire - COPD (SGRQ-C), allows all aspects related to the health status of patients with COPD to be considered [16].

The primary aim of this study was to describe the HRQL of patients with COPD in Extremadura, one of Spain's 17 autonomous communities, both in terms of their general quality of life using the EQ-5D-5L, and their specific quality of life using the SGRQ-C. The secondary objective was to explore the relationship between HRQL and several socio-demographic and clinical characteristics of the patients. The data used are part of a study on the total socioeconomic burden of COPD in Extremadura, which describes the economic costs of COPD, and the association between poorer HRQL and increased consumption of health resources [17]. The information provided in this paper complements those results and may prove useful in the design of preventive measures and in decision making related to the appropriate management of COPD.

\section{Methods}

\section{Subject population}

The Extremadura Health Service includes eight different Health Areas. Health Areas are geographical divisions with a relatively decentralized management of primary care services in each area, as is the case across all Spanish autonomous communities. The eight Health Areas of Extremadura are in turn subdivided into a total of 114 Basic Health Areas. According to the Extremadura Health System, there were a total of 9622 people diagnosed with COPD in Extremadura in April 2015 (79.9\% males, $79.3 \% \geq 65$ years), spread across its eight Health Areas. Therefore, our population was 9622 individuals.

\section{Study design}

This study uses data from a larger study dedicated to the socio-economic burden of COPD in Extremadura [17]. This was a cross-sectional observational study that used probabilistic sampling stratified by Health Area in order to obtain a representative sample of patients with COPD in Extremadura. In the first stage, a randomized sample representative of the adult population diagnosed with COPD in Extremadura $(n=386,95 \%$ confidence level,
5\% sampling error) was calculated based on the prevalence of COPD in the population aged 18 and over in Extremadura. In the second stage, two age group quotas (under 65 years of age and 65 and over) and two gender quotas per age group were established within the sample. These represented the different age and gender prevalence groups in each of the eight Health Areas of Extremadura. We then randomly selected 18 Basic Health Areas distributed across the eight Health Areas of Extremadura, proportionately to the number of Basic Health Areas in each Health Area. The number of patients and age/gender quotas to enrol in each Basic Health Zone were assigned in such a way that the theoretical sample was proportionally distributed across Health Areas. Likewise, within each Health Area, the quotas were proportionally distributed across age and gender of the population with COPD residing in each of the Health Areas.

The present study included people diagnosed with COPD according to the Global Initiative for Chronic Obstructive Lung Disease (GOLD) classification criteria [18] at least 12 months before their inclusion in the study, 18 years of age or older, residents of Extremadura whose primary care electronic medical records were available for the 12 months prior to the collection of the data, who provided informed consent to participate in the study in accordance with local regulations. Patients with any limitation that, according to the researchers' best judgement, could affect the reliability of their answers were excluded (e.g., patients without knowledge of Spanish, or patients with any evident cognitive impairment). Patients who had participated in any clinical trial in the 12 months prior to the collection of data and pregnant women were also excluded.

A total of 18 previously trained researchers participated in the data collection process, one in each of the 18 Basic Health Areas selected. Researchers received a randomly ordered list of all the patients diagnosed with COPD who resided in their corresponding Basic Health Zone. The patients' name, contact telephone number, and address were included in the list as they appeared on their clinical record. This information was disclosed to field researchers but was never available to the signing authors of this manuscript. Researchers contacted patients over the telephone following the order in their list. Whenever a patient was not available on the telephone, researchers contacted the next patient on the list. Once telephone contact was established, researchers verified with the patient that inclusion/exclusion criteria were met and, if so, asked the patient to meet in person either in the patient's home or in their primary care centre, whichever was preferred by the patient. Patients were recruited this way until all age and gender quotas were completed for each Basic Health Zone. The reasons 
reported by researchers for not enrolling a patient included: the patient does not feel comfortable talking to a doctor, the patient feels nervous and apprehensive about the study, the patient will not be available for a while (e.g. holidays), the patient did not consent to participate, the patient was not reachable after several calls, the patient had a cognitive deficit (Alzheimer's disease), the patient has moved to another autonomous community or to another Basic Health Area, there was no contact information on the clinical record, and the patient did not recognize having any respiratory disease.

The fieldwork was carried out from July 10th to November 11th, 2015, and included one single visit per patient. Besides collecting information related to healthcare and non-healthcare resource utilization (results published elsewhere [17]), information was collected on patients' quality of life at the time of the visit using the EQ-5D-5L questionnaire (general quality of life) and the SGRQ-C questionnaire (quality of life of patients with airway obstruction). Information on comorbidities was collected directly from the patients' electronic clinical records. Prior to data collection, patients were informed about the study objectives and data confidentiality. Patients provided their written informed consent to participate in the study and to release information, according to the Spanish legislation. Permission to perform the study was obtained from the Clinical Research Ethics Committee of the University Hospital Infanta Cristina (Badajoz).

\section{Study variables}

\section{Health-related quality of life}

Two validated questionnaires were used to assess the HRQL of the patients. The first questionnaire was the EQ-5D-5L, which was used to measure general HRQL at the time of the visit, as reported by the patient. This questionnaire gathers information relative to five healthrelated dimensions (mobility, self-care, daily activities, pain or discomfort, and anxiety or depression), and each dimension has five response options depending on the intensity level of the problem (no problems, slight problems, moderate problems, severe problems, and extreme problems). Thus, the EQ-5D-5L allows for the collection of a total of 3125 possible health states. Each state is assigned a utility value based on the rates validated for Spain [19], which ranges from 0 (equivalent to death) to 1 (perfect health status). Values below zero are possible and are understood as a health status that is worse than death. This questionnaire further provides a visual analogue scale (VAS) where the patient self-evaluates their health. The VAS ranges from 0 (worst imaginable state) to 100 (best imaginable state) [20].

The second questionnaire was the SGRQ-C, which quantifies the impact of COPD and/or asthma on health and well-being, as perceived by the patients. The questionnaire consists of 50 items divided into three component scores: Symptoms, Activity and Impacts. The Symptoms score refers to the frequency and severity of respiratory symptoms, the Activity score is indicative of dyspnoea-related activity limitations, and the Impacts score shows the psychological and social changes produced by the disease. The items are formulated in two different manners. The first method involves five response options, allowing only a single option to be marked. The second method involves a dichotomous answer: yes/no. A Total score is calculated taking into account all three component scores. All scores range between 0 (without any impact on the quality of life) and 100 (maximum impact on the quality of life) [21]. Researchers provided patients with an electronic tablet containing both questionnaires to be self-administered by the patients.

\section{Level of severity}

The level of severity according to the GOLD scale (levels I to IV, where I corresponds to mild airflow limitation and IV corresponds to very severe airflow limitation, in patients with $\left.\mathrm{FEV}_{1} / \mathrm{FVC}<0.70\right)[18]$ was not available in the primary care clinical records of a large number of patients. As we had no access to clinical records from pulmonology services (these generally include the GOLD classification), we used three complementary sources of information for the elaboration of a single severity variable. Accordingly, the following steps were taken to determine COPD severity: first, the GOLD classification of the patient was used if it was included in the clinical records (10.6\% of the patients). Second, in the absence of a GOLD classification, the GOLD classification was calculated from the $\mathrm{FEV}_{1} \%$ predicted values as long as these data were indicated in the clinical records (30.3\% of the patients). This calculation was done following the GOLD classification of airflow limitation severity criteria [18]. Third, in cases where no GOLD classification or $\mathrm{FEV}_{1} \%$ data were available, we used the description made by the doctor in the patient's medical records $(0.8 \%$ of the patients). Finally, if all the previous data were not available, an "unknown/not available" severity level was assigned. In our sample $(n=386), 58.3 \%$ of patients (226 patients) lacked information on severity level.

\section{Statistical analysis}

Descriptive statistics (number of valid cases, mean, and standard deviation) were calculated for continuous variables, and frequencies and percentages were calculated for categorical variables. An analysis was performed using the total sample, and comparisons were made based on the level of severity, gender, and age group. For the analysis according to severity, GOLD I and II categories were grouped together, and GOLD III and IV 
categories were grouped together with the aim of optimizing the statistical comparison. For the comparison of a quantitative variable with a qualitative variable, nonparametric techniques were used (Mann-Whitney U and Kruskal-Wallis $U$ tests). For the comparison of two qualitative variables, the Chi-square test was used. To analyse the explanatory factors of HRQL (utility and SGRQ-C total score), a stepwise multiple regression was used. The regression variables were gender, age in years, education level (no education and primary education vs. secondary and university education), COPD severity level (GOLD I-II vs. GOLD III-IV), number of exacerbations in the last 12 months, and number of comorbidities (this variable includes all comorbidities reported in the patient's clinical record that were current at the time of the interview). Values of $\mathrm{F} \leq 0.05$ and $\mathrm{F}>0.10$ were established as input and output criteria for the explanatory variables, respectively. This process was repeated until the model did not improve. Finally, to correlate the scores of the questionnaires, Spearman's rho correlation coefficient was used. For all analyses, the limit of statistical significance was $p<0.05$. The data were analysed with the statistical package IBM SPSS Statistics V22.0.

\section{Results}

A valid sample of 386 patients was obtained. In total, 294. (76.2\%) were male. In addition, 306 (79.3\%) were 65 years or older with an average age of $71.8 \pm 10.3$ years old. Table 1 shows the sociodemographic and clinical characteristics of the sample.

\section{EQ-5D-5L: dimensions}

The health-related dimensions most affected by COPD were Mobility and Pain/Discomfort. The dimension with the highest percentage of severe or extreme problems was Daily Activities. The dimensions with the least associated problems were Self-Care and Anxiety/Depression (Fig. 1a).

All dimensions showed statistically significant differences by severity level of COPD. In general, patients classified as GOLD I-II had fewer problems compared with those classified as GOLD III-IV. These differences were especially evident for the Mobility and Pain/Discomfort dimensions where the proportion of GOLD I-II patients without problems was twice that of GOLD IIIIV patients (Fig. 1b).

Furthermore, women endured a higher impact than men in all health-related dimensions. Specifically, in the dimensions of Pain/Discomfort, Self-Care, and Anxiety/ Depression, the percentage of women with severe or extreme problems was twice that of men (Fig. 1c).

Moreover, there were statistically significant differences in the Daily Activities and Self-Care dimensions by age group. Patients aged 65 or older reported more severe or extreme problems compared with those younger than 65 years of age (Fig. 1d).

\section{EQ-5D-5L: utility}

The average utility was $0.72 \pm 0.31$ and varied significantly depending on the level of severity. The post hoc analyses showed no differences between GOLD I and GOLD II categories and between GOLD III and GOLD IV categories. However, differences were found between both groups (GOLD I-II vs GOLD III-IV). The average utility was higher for men than for women, and higher for patients under 65 years of age than for patients 65 years and older (Table 2).

\section{EQ-5D-5L: visual analogue scale}

The VAS mean score was $58.6 \pm 21.9$, but varied significantly by gender, with women reporting a poorer selfassessment of their HRQL than men. Differences were also observed according to level of COPD severity. However, the distribution of utility by severity level was heterogeneous, for differences were only identified between GOLD categories II and III but not among the rest of the groups (Table 2).

\section{SGRQ-C score}

The average total SGRQ-C score was $40.9 \pm 25.0$ points, with the Activity component having the greatest impact $(52.7 \pm 28.7$ points $)$ on quality of life. The total score showed statistically significant differences by gender and by level of severity. The post hoc analyses did not indicate differences between GOLD I and GOLD II categories nor between GOLD III and GOLD IV categories. However, differences between both groups were found, with greater impact in advanced stages of severity. Women reported a greater average total score than men. The Symptoms component showed a greater impact in advanced stages of severity. The Activity component also revealed greater limitations due to dyspnoea in advanced stages, in women, and in older patients. The Impacts component showed greater psychological and social impact in advanced stages and in women (Table 3).

\section{Factors associated with HRQL}

The results of both regression analyses indicate that having suffered exacerbations in the last year, presenting a higher level of severity, being a woman, and having no education or primary education (as opposed to having a secondary or university education) are related to worse HRQL scores. Patient's age and number of comorbidities were not statistically significant (Table 4). 
Table 1 Sociodemographic and clinical characteristics of the sample

\begin{tabular}{lll}
\hline Variable & Subcategory & Total \\
\hline Gender (\%) & Male & $76.2 \%$ \\
& Female & $23.8 \%$
\end{tabular}

Age in years (mean $\pm S D)$

Age group (\%)

Smoking history (\%)

Daily cigarettes (mean $\pm \mathrm{SD}$ )

Education level (\%)

$\mathrm{FEV}_{1} / \mathrm{FVC}(\text { mean } \pm \mathrm{SD})^{\mathrm{a}}$

$\mathrm{FEV}_{1} \%(\text { mean } \pm \mathrm{SD})^{\mathrm{b}}$

Level of severity (\%)

Presence of exacerbations in the last 12 months (\%)

Number of exacerbations in the last 12 months (mean $\pm \mathrm{SD})^{c}$

Number of comorbidities (mean \pm $\mathrm{SD})$

Main comorbidities (\%)

Under $65 \quad 20.7 \%$

65 years or older $\quad 79.3 \%$

Current smoker $\quad 16.7 \%$

Ex-smoker

Never smoked

$69.6 \%$

$13.7 \%$

Ex-smokers

$14.1 \pm$

10.3

$27.3 \pm$

16.4

Does not know how to $\quad 6.0 \%$ read or write

No education $\quad 33.9 \%$

Primary education $\quad 35.9 \%$

Secondary education $\quad 18.5 \%$

University education $\quad 5.7 \%$

Early retirement/retired

Actively working

Domestic work

Unemployed

Permanent leave

Temporary leave$$
\begin{aligned}
& \mathrm{GO} \\
& \mathrm{GO} \\
& \mathrm{G} \\
& \mathrm{G} \\
& \mathrm{U} \\
& \mathrm{H}
\end{aligned}
$$

GOLD ॥

GOLD III

GOLD IV

$\begin{array}{lc}\begin{array}{l}\text { Cardiovascular } \\ \text { comorbidity }^{d}\end{array} & 57.5 \% \\ \begin{array}{l}\text { Dyslipidaemia/Lipid } \\ \text { metabolism disorder }\end{array} & 41.5 \% \\ \begin{array}{l}\text { Uncomplicated } \\ \text { hypertension }\end{array} & 38.3 \% \\ \begin{array}{l}\text { Diabetes Mellitus (type } \\ 1+\text { type 2) }\end{array} & 27.2 \% \\ & \end{array}$

$60.3 \pm$
Smokers

Unknown/not available
Table 1 Sociodemographic and clinical characteristics of the sample (Continued)

\begin{tabular}{lll}
\hline Variable & Subcategory & Total \\
\hline & Arthritis/Arthrosis & $20.0 \%$ \\
& Cancer/malignancy & $14.8 \%$ \\
& Hypertension with target & $13.0 \%$ \\
& organ involvement & \\
& Anaemia & $6.7 \%$ \\
& Depression & $6.2 \%$ \\
& Asthma & $6.0 \%$ \\
& Osteoporosis & $3.9 \%$ \\
BMI (mean \pm SD) & & $30.0 \pm$ \\
Classification of BMl according to & Insufficient weight & $0.8 \%$ \\
the WHO (\%) & Normal weight & $3.4 \%$ \\
& Overweight & $16.1 \%$ \\
& Obesity & $18.4 \%$ \\
& Unknown/not available & $61.4 \%$ \\
\hline
\end{tabular}

$S D$ standard deviation, $F E V_{1}$ forced expiratory volume in the first second, absolute value, $F V C$ forced vital capacity, $F E V_{1} \%$ forced expiratory volume in the first second, percentage value, COPD chronic obstructive pulmonary disease, BMI Body Mass Index, MRC Medical Research Council, WHO World Health Organization. Number of valid cases: 386 , unless specifically indicated. ${ }^{a}$ Number of valid cases: 123 ; ${ }^{b}$ Number of valid cases: 140 ; ${ }^{\mathrm{C}}$ Number of valid cases: $215 ;{ }^{\mathrm{d}}$ Includes unspecified cardiac arrhythmia, atherosclerosis or peripheral arterial disease, valvular heart disease, atrial fibrillation/atrial flutter, acute myocardial infarction, heart failure, cardiac ischaemia with angina, cardiac ischaemia without angina, other cardiac diseases, other cardiovascular diseases, other cardiovascular signs/symptoms, and paroxysmal tachycardia; eNumber of valid cases: 149

\section{Correlation between the SGRQ-C and the EQ-5D-5L questionnaires}

Utility, as per the EQ-5D-5L, was strongly correlated with the total score of the SGRQ-C (rho $=-0.758)$. This was higher than the correlation between each of their components separately. On the other hand, the VAS score showed a moderate correlation with the Total SGRQ-C score (rho $=-0.566$ ), as well as with the Activity and the Impacts components, and a low correlation with the Symptoms component.

\section{Discussion}

Few studies have estimated the HRQL of patients with COPD in Spain. To our knowledge, this is the first study to shed light on the relationship between HRQL and several clinical and socio-demographic characteristics of patients with COPD, including severity level, representative of the COPD population in an autonomous community (Extremadura). The main strengths of the present study are the use of a representative sample of adult patients in Extremadura and the use of two different HRQL questionnaires based on PRO measures: a general quality of life questionnaire and a specific quality of life questionnaire. 


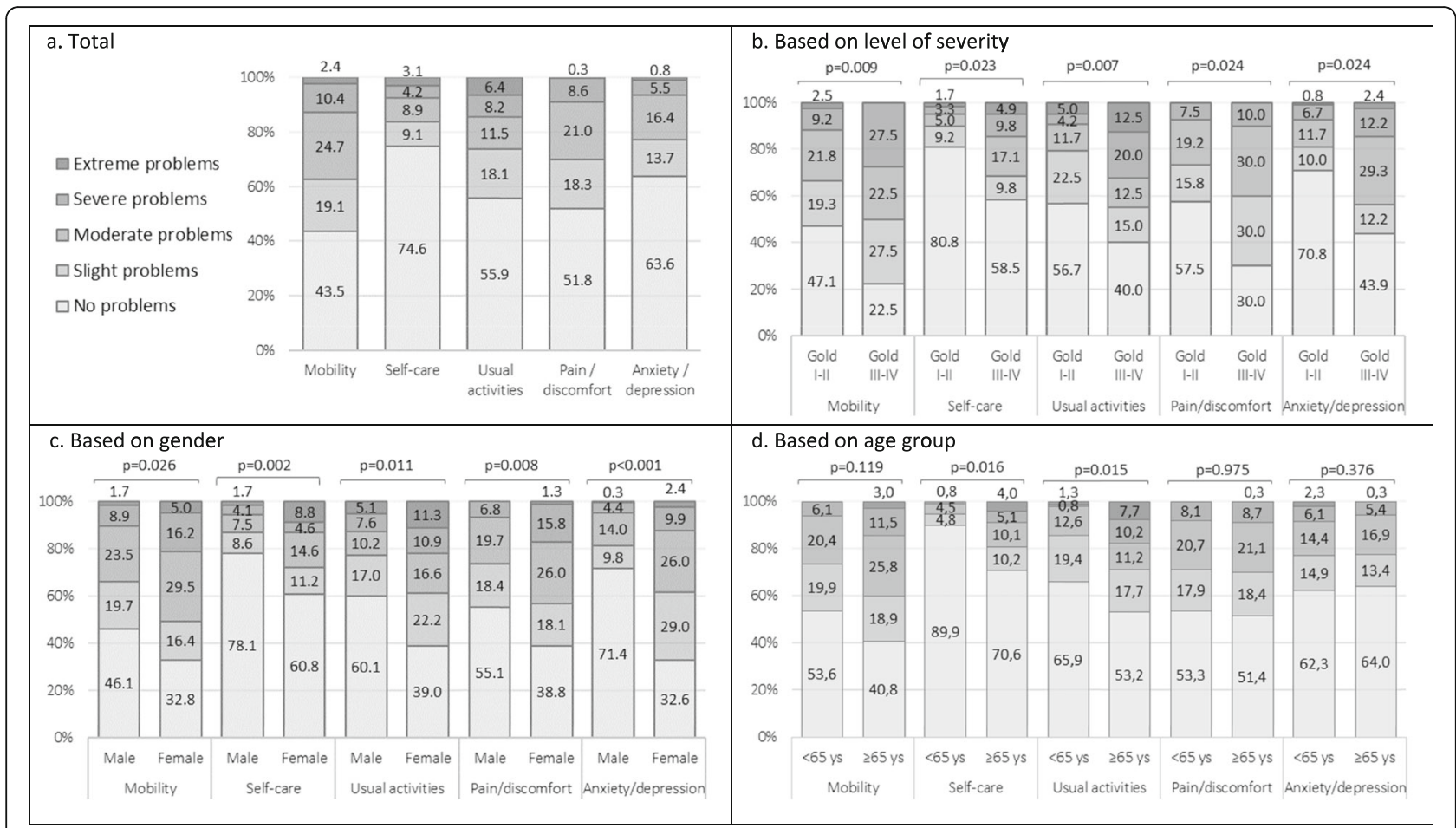

Fig. 1 EQ-5D-5L dimensions. Total (a), based on level of severity (b), based of gender (c), and based on age group (d)

The total SGRQ-C score of our sample was 40.9 points. This value is similar to that reported by some authors [22, 23] but lower than figures published by others (approximately 44 points) [24, 25]. This difference may be attributed to previous studies using samples with a higher percentage of patients in advanced COPD stages compared with our sample. Pathologies like depression or anxiety significantly influence the total SGRQ-C score [25], contribute to poorer HRQL among these patients [26], and are more often associated with COPD compared with other chronic diseases [27]. In our study, the Anxiety/Depression dimension of the EQ-5D-5L identified a low percentage of patients with some type of problem $(n=140,36.4 \%)$. However, the breakdown by level of severity revealed a greater prevalence of Anxiety/Depression in patients classified as GOLD III-IV $(N=23,56.1 \%)$ compared with patients classified as GOLD I-II $(N=35,29.8 \%)$. Finally, the average utility of our sample was 0.72 , which is lower than that reported in previous studies [2, 24, 28]. Therefore, the presence of Anxiety/Depression, advanced stages of disease (GOLD III-IV), and worse health outcomes (reduced utility in EQ-5D-5L and increased Total SGRQ-C score) are interrelated. We believe that our results might reinforce the notion that grouping GOLD cases as I-II and III-IV may be useful and appropriate when analysing the impact of COPD severity on the HRQL of patients [23].
The multivariate analysis revealed that HRQL is influenced by level of COPD severity, number of exacerbations in the last 12 months, education level, and gender. Indeed, we found that advanced stages of COPD and a higher number of exacerbations were related to the worst results in HRQL. These findings are in line with previous studies $[29,30]$, and underline the importance of developing research on COPD treatments that may hinder exacerbations and lower the progression of the disease. Poor education and being a woman were also associated with worse levels of HRQL. These findings are also in line with previous studies [25, 28, 31, 32], and suggest that any COPD prevention and treatment program should be designed to reach the lower educated segments of the population, and the female population.

Finally, Wacker et al. [24] reported a moderate correlation between the EQ-5D-3 L and the SGRQ-C (-0.56). The correlation reported between both instruments in the present study is higher $(-0.76)$, which may be explained by the use of the 5-level EQ-5D instead of the 3level EQ-5D, providing greater sensitivity in the assessment of HRQL. On the other hand, the same study reported a stronger correlation between the VAS score and the SGRQ-C score $(-0.65)$ compared to our study $(-0.57)$.

Of course, this study is not without limitations. First, the primary objective of our observational study was to estimate the socio-economic burden of COPD in 
Table 2 EQ-5D-5L: Utility and VAS. Total and subgroups (level of severity, gender and age group)

\begin{tabular}{|c|c|c|c|c|c|}
\hline \multirow[t]{2}{*}{ Subgroups } & \multirow{2}{*}{$\begin{array}{l}\text { Number } \\
\text { of valid } \\
\text { cases }\end{array}$} & \multicolumn{2}{|l|}{ Utility } & \multicolumn{2}{|l|}{ VAS } \\
\hline & & mean $\pm S D$ & $p$-value & mean $\pm S D$ & $p$-value \\
\hline \multicolumn{6}{|c|}{ Level of severity } \\
\hline GOLD I & 41 & $0.74 \pm 0.35$ & 0.003 & $59.8 \pm 24.4$ & 0.040 \\
\hline GOLD ॥ & 79 & $0.77 \pm 0.26$ & & $62.4 \pm 20.7$ & \\
\hline GOLD III & 35 & $0.58 \pm 0.31$ & & $50.0 \pm 21.2$ & \\
\hline GOLD IV & 5 & $0.48 \pm 0.45$ & & $65.7 \pm 30.1$ & \\
\hline \multicolumn{6}{|c|}{ Gender } \\
\hline Male & 308 & $0.76 \pm 0.28$ & $<0.001$ & $60.5 \pm 22.0$ & 0.001 \\
\hline Female & 78 & $0.58 \pm 0.38$ & & $51.3 \pm 20.0$ & \\
\hline \multicolumn{6}{|c|}{ Age group } \\
\hline Under 65 & 80 & $0.81 \pm 0.22$ & 0.023 & $59.3 \pm 20.7$ & 0.837 \\
\hline 65 years or older & 306 & $0.70 \pm 0.32$ & & $58.5 \pm 22.3$ & \\
\hline Total & 386 & $0.72 \pm 0.31$ & & $58.6 \pm 21.9$ & \\
\hline
\end{tabular}

EQ-5D-5L EuroQol - 5 dimensions - 5 levels, VAS visual analogue scale, SD standard deviation, COPD chronic obstructive pulmonary disease

Extremadura [17], while measuring the HRQL of patients was a secondary objective. Therefore, given that our sample size was designed to analyse the economic burden of COPD it may not have sufficient statistical power for performing HRQL analyses. Second, the sample design with affixation by gender and age groups could potentially influence the results of the questionnaires, given that these variables influence HRQL. Therefore, populations with different population pyramids and different prevalence rates could yield different results. Third, the severity level of COPD corresponds to a variable constructed from information provided by the clinical history. However, this information was missing for the majority of the participants (58.3\%). Indeed, although all patients were diagnosed using spirometry, primary care records only collect information on the number of spirometries that the patient had in the past 12 months, but do not necessarily provide the results of those spirometries, nor the GOLD classification of the patient. Had data been collected from pulmonology services' clinical records, information on lung function impairment, and other clinical variables such as BMI and number of exacerbations in the past 12 months, would have been available for all patients. Fourth, in our

Table 3 SGRQ-C Score. Total and based on subgroups (level of severity, gender and age group)

\begin{tabular}{|c|c|c|c|c|c|c|c|c|c|}
\hline \multirow[t]{2}{*}{ Subgroups } & \multirow{2}{*}{$\begin{array}{l}\text { Number } \\
\text { of valid } \\
\text { cases }\end{array}$} & \multicolumn{2}{|l|}{ Symptoms } & \multicolumn{2}{|l|}{ Activity } & \multicolumn{2}{|l|}{ Impacts } & \multicolumn{2}{|l|}{ Total score } \\
\hline & & mean $\pm S D$ & $p$-value & mean $\pm S D$ & $p$-value & mean $\pm S D$ & $p$-value & mean $\pm S D$ & $p$-value \\
\hline \multicolumn{10}{|l|}{ Level of severity } \\
\hline GOLD I & 41 & $38.6 \pm 22.6$ & $<0.001$ & $45.7 \pm 28.8$ & $<0.001$ & $27.6 \pm 26.8$ & 0.001 & $35.1 \pm 25.1$ & $<0.001$ \\
\hline GOLD II & 79 & $40.3 \pm 22.1$ & & $53.2 \pm 25.9$ & & $33.4 \pm 26.8$ & & $40.7 \pm 23.6$ & \\
\hline GOLD III & 35 & $62.3 \pm 23.0$ & & $73.5 \pm 23.3$ & & $54.8 \pm 28.9$ & & $61.9 \pm 24.8$ & \\
\hline GOLD IV & 5 & $55.1 \pm 26.1$ & & $70.1 \pm 25.5$ & & $46.3 \pm 33.7$ & & $55.2 \pm 28.2$ & \\
\hline \multicolumn{10}{|l|}{ Gender } \\
\hline Male & 308 & $41.6 \pm 23.1$ & 0.256 & $50.6 \pm 28.5$ & 0.004 & $31.1 \pm 27.2$ & 0.002 & $39.0 \pm 24.9$ & 0.003 \\
\hline Female & 78 & $44.4 \pm 23.3$ & & $61.3 \pm 28.0$ & & $42.0 \pm 26.9$ & & $48.4 \pm 24.3$ & \\
\hline \multicolumn{10}{|l|}{ Age group } \\
\hline Under 65 & 80 & $39.8 \pm 22.2$ & 0.376 & $44.7 \pm 28.7$ & 0.006 & $28.8 \pm 24.7$ & 0.167 & $35.6 \pm 23.4$ & 0.052 \\
\hline 65 years or older & 306 & $42.8 \pm 23.4$ & & $54.8 \pm 28.4$ & & $34.5 \pm 28.1$ & & $42.2 \pm 25.3$ & \\
\hline Total & 386 & $42.2 \pm 23.2$ & & $52.7 \pm 28.7$ & & $33.3 \pm 27.5$ & & $40.9 \pm 25.0$ & \\
\hline
\end{tabular}

SGRQ-C St. George Respiratory Questionnaire - COPD, COPD chronic obstructive pulmonary disease, SD standard deviation. Columns 3 to 6 show the mean and $\mathrm{SD}$ that correspond to the number of valid cases shown on column 2 
Table 4 Results of stepwise multiple regression models for utility (EQ-5D-5L) and total score (SGRQ-C)

\begin{tabular}{llllll}
\hline Dependent variable & Explanatory variables $^{\mathrm{a}}$ & B coefficient $^{\mathrm{b}}$ & $p_{\text {-value }}$ & $95 \% \mathrm{Cl}$ & Coefficient of determination \\
\hline Total score (SGRQ-C) & Intercept & 35.604 & $<0.001$ & $(29.278 ;-41.930)$ & 0.431 \\
& Level of severity & 21.267 & $<0.001$ & $(12.119 ; 30.416)$ \\
& Number of exacerbations in the & 8.445 & $<0.001$ & $(5.140 ; 11.749)$ \\
& past 12 months & & & \\
& Education level & -18.147 & $<0.001$ & $(-27.469 ;-8.824)$ \\
& Gender & 19.693 & $<0.001$ & $(8.864 ; 30.523)$ \\
Utility (EQ-5D-5L) & Intercept & 0.763 & $<0.001$ & $(0.684 ;-0.842)$ \\
& Number of exacerbations in the last & -0.086 & $<0.001$ & $(-0.127 ;-0.044)$ \\
& 12 months & & & \\
& Level of severity & -0.176 & 0.003 & $(-0.291 ;-0.061)$ \\
& Education level & 0.188 & 0.002 & $(0.071 ; 0.305)$ \\
& Gender & -0.157 & 0.024 & $(-0.293 ;-0.021)$ \\
\hline
\end{tabular}

Cl confidence interval, EQ-5D-5L EuroQol - 5 dimensions - 5 levels, SGRQ-C St. George Respiratory Questionnaire - COPD

${ }^{a}$ Explanatory variables included in the models: gender (0: male (reference category)/1: female), age in years, education level (0: no education and primary education (reference category)/1: secondary and university education), level of severity (0: GOLD I-II (reference category)/1: GOLD III-IV), number of exacerbations in the last 12 months and number of comorbidities

${ }^{\mathrm{b}}$ Unstandardized B coefficient

sample, $13.7 \%$ of patients never smoked, which is less than that reported in previous studies for Spain [2, 3]. Multiple studies highlight the significant prevalence of COPD among never smokers [33]. However, if we agree that COPD requires an exposure to smoking or to biomass inhalation, then we cannot discard the possibility of an overdiagnosis of COPD in the population of Extremadura, particularly in the elderly population as the $\mathrm{FEV}_{1} \%$ ratio falls with age [2]. Fifth, we have no information on whether particular types of patients were more likely to agree to participate in the study than others. For example, if working patients were systematically more difficult to reach than patients who do not work or who work from home, the sample might suffer from a certain degree of socioeconomic bias. Sixth, the cross-sectional design of our study only allowed us to analyse the association between variables; it did not allow us to evaluate any causal relationship. Finally, our study is only representative of the COPD patient population of Extremadura, one Spanish autonomous community. Extremadura is only one of the 17 autonomous communities in Spain and gathers only $2.35 \%$ of the total Spanish population. Although this may limit the generalizability of our results to the rest of the country, the gender, age, socioeconomic distribution, and access to health-care of the population are in line with average values in Spain [34]. Therefore, there is no reason to assume that the HRQL and its association with severity level, gender, and education of the patients differ substantially from other regions in Spain.

\section{Conclusion}

This study sheds new light on the current HRQL of patients with COPD in one Spanish autonomous community (Extremadura). We found that the dimensions of HRQL that were most affected by COPD were mobility, daily activities, and pain or discomfort. We also found that severity of COPD, exacerbations, low education level, and being female are factors that significantly worsen HRQL and each of its dimensions. Health managers should consider these interactions as part of their usual activity in the management of COPD with the ultimate goal of meeting the specific needs of their patients and increasing their HRQL. In particular, any program, strategy, or policy of health promotion regarding COPD should not overlook the importance of preventing exacerbations, where adherence to treatment plays a fundamental role, as well as designing campaigns that target women and less-educated social groups. This study can serve as an example for future HRQL estimations in other autonomous communities or nationwide, with the aim to show the real magnitude of the impact of COPD in Spain. This could help the Spanish National Health System to design, prioritize resources, and improve preventive programmes to enhance HRQL for all COPD patients, in all regions of Spain.

\section{Abbreviations}

BMI: Body Mass Index; Cl: Confidence Interval; COPD: Chronic Obstructive Pulmonary Disease; EQ-5D-3L: EuroQoL-5 Dimensions-3 Levels; EQ-5D5L: EuroQoL-5 Dimensions-5 Levels; FEV ${ }_{1}$ : Forced Expiratory Volume the First Second, in absolute value; FEV $1 \%$ : Forced Expiratory Volume the First Second, in percentage value; FVC: Forced Vital Capacity; GOLD: Global Initiative for Chronic Obstructive Lung Disease; HRQL: Health-Related Quality of Life; MRC: Medical Research Council; SD: Standard Deviation; SGRQ-C: St. George's Respiratory Questionnaire; VAS: Visual Analogue Scale; WHO: World Health Organization

\section{Acknowledgements}

The authors wish to thank the patients and their caregivers who provided their time to participate in the study. In addition, we would like to thank 
José Luis Sánchez Chorro for his help in coordinating the data collection process.

Likewise, we would like to thank the Collaborative Working Group EPOCExtremadura who participated in the recruitment and data collection processes, and whose members are listed below:

Susana Alonso García De Vinuesa, Basic Health Area of Mérida - Obispo Paulo

Anastasia Bejarano Cebrián, Basic Health Area of Arroyo de la Luz Gema Beorlegui Aristu, Basic Health Area of Plasencia - Luis de Toro José Carlos Domínguez Rodríguez, Basic Health Area of Coria Lorenzo Fernández Prieto, Basic Health Area of Llerena Ma Carmen Galán Parra, Basic Health Area of Casas del Castañar Aurelia María García Martínez, Basic Health Area of Don Benito Oeste Rosa Ma García-Adámez Soto, Basic Health Area of Zalamea de la Serena Ma Mercedes Guío Carretero, Basic Health Area of Hornachos Laura Horrillo Murillo, Basic Health Area of Trujillo Urbano Ma Teresa Laso Martínez, Basic Health Area of Cáceres - Norte Laura Martín Jurado, Basic Health Area of Oliva de la Frontera Miguel A. Martín de la Nava, Basic Health Area of Zorita Ma Eugenia Martínez Domínguez, Basic Health Area of Navalmoral de la Mata Carmen Morillo Pantoja, Basic Health Area of Badajoz - Zona Centro

Olga Ortiz Rodríguez, Basic Health Area of Zafra

Manuela Pardo Amaya, Basic Health Area of Talarrubias

Ana Ma Villalba Doblas, Basic Health Area of Badajoz - La Paz

\section{Author's contributions}

$M M, R V$ and AHV participated in the conception and design of the study. CC and the CWG EPOC-Extremadura participated in the acquisition of data. MM and RV participated in the analysis and interpretation of data. MM wrote the draft of the manuscript. All authors critically revised the manuscript for important intellectual content and approved the final version to be published.

\section{Authors' information}

Not applicable.

\section{Funding}

This work was supported by Chiesi España.

\section{Availability of data and materials}

Data can be shared upon contact with the correspondence author.

\section{Ethics approval and consent to participate}

Patients provided written informed consent to participate in the study and to release information, according to the Spanish legislation. Permission to perform the study was obtained from the Clinical Research Ethics Committee of the University Hospital Infanta Cristina (Badajoz).

\section{Consent for publication}

Not applicable.

\section{Competing interests}

The authors declare that they have no competing interests.

\section{Author details}

${ }^{1}$ Fundación Weber, Calle Moreto 17, 5 D, 28014, Madrid, Spain. ${ }^{2}$ Universidad de Castilla-La Mancha, Cobertizo de San Pedro Mártir s/n, 45071 Toledo, Spain. ${ }^{3}$ Servicio Extremeño de Salud, Avenida de las Américas 2, 06800 Mérida, Badajoz, Spain.

Received: 26 June 2018 Accepted: 13 November 2019

Published online: 30 December 2019

\section{References}

1. Miravitlles M, Soler-Cataluña JJ, Calle M, Molina J, Almagro P, Quintano JA, et al. Guía española de la EPOC (GesEPOC) 2017. Tratamiento farmacológico de la EPOC estable. Arch Bronconeumol. 2017;53:324-35.

2. Miravitlles M, Soriano JB, García-Río F, Muñoz L, Duran-Tauleria E, Sanchez G, et al. Prevalence of COPD in Spain: impact of undiagnosed COPD on quality of life and daily life activities. Thorax. 2009;64:863-8.

3. Sobradillo Peña V, Miravitlles M, Gabriel R, Jiménez-Ruiz CA, Villasante C, Masa JF, et al. Geographic variations in prevalence and underdiagnosis of
COPD: results of the IBERPOC multicentre epidemiological study. Chest. 2000;118:981-9.

4. Instituto Nacional de Estadística. Enfermedades Crónicas. Problemas o enfermedades crónicas o de larga evolución padecidas en los últimos 12 meses y diagnosticadas por un médico en población adulta según sexo y comunidad autónoma. Población de 15 y más años. 2012. http://www.ine. es/jaxi/Tabla.htm?path=/t15/p419/a2011/p01/10/\&file=01030.px\&L=0. Accessed 31 Aug 2016.

5. Hidalgo Sierra V, Hernández Mezquita MÁ, Palomo Cobos L, García Sánchez M, Diego Castellanos R, Jodra Sánchez S, et al. Utilidad del dispositivo portátil Piko-6 para la detección precoz de la enfermedad pulmonar obstructiva crónica en atención primaria. Arch Bronconeumol. 2018;54:460-6.

6. World Health Organization, WHO. The top 10 causes of death. 2015. http:// www.who.int/mediacentre/factsheets/fs310/en/. Accessed 21 Sept 2017.

7. World Health Organization, WHO. Burden of COPD. 2017. http://www.who. int/respiratory/copd/burden/en/. Accessed 15 Feb 2017.

8. Pedone C, Giua R, Scichilone N, Bellia V, Antonelli-Incalzi R. GOLD staging system is appropriate to predict mortality in older people with chronic obstructive pulmonary disease. Arch Bronconeumol. 2018;54(7):365-70.

9. Masa JF, Sobradillo V, Villasante C, Jiménez-Ruiz CA, Fernández-Fau L, Viejo $J L$, et al. Costes de la EPOC en España. Estimación a partir de un estudio epidemiológico poblacional. Arch Bronconeumol. 2004;40:72-9.

10. Espinosa Mesa N, Perea Herrera R, Vega García SS, Bermejo Guillén G, Lahoz Rallo B. Calidad de vida y situación sociosanitaria de los pacientes con EPOC. Med Fam. 2005:6:137-44.

11. Miravitlles M, Murio C, Guerrero T, Gisbert R. Costs of chronic bronchitis and COPD: a 1-year follow-up study. Chest. 2003;123:784-91.

12. Dubé B-P, Vermeulen F, Laveneziana P. Exertional dyspnoea in chronic respiratory diseases: from physiology to clinical application. Arch Bronconeumol. 2017;53:62-70.

13. Rubio MC, Hermosa JL, Soler-Cataluña JJ, López-Campos JL, Navarrete BA, Soriano JB, et al. Medical care according to risk level and adaptation to Spanish COPD guidelines (Gesepoc): the Epoconsul study. Arch Bronconeumol. 2018:54:270-9.

14. Jones PW. Health status measurement in chronic obstructive pulmonary disease. Thorax. 2001;56:880-7 Accessed 19 Oct 2017.

15. Cazzola M, MacNee W, Martinez FJ, Rabe KF, Franciosi LG, Barnes PJ, et al. Outcomes for COPD pharmacological trials: from lung function to biomarkers. Eur Respir J. 2008;31:416-69.

16. Daudey L, Peters JB, Molema J, Dekhuijzen PR, Prins JB, Heijdra YF, et al. Health status in COPD cannot be measured by the St George's respiratory questionnaire alone: an evaluation of the underlying concepts of this questionnaire. Respir Res. 2010;11:98.

17. Merino M, Villoro R, Hidalgo-Vega A, Carmona C. Collaborative working group EPOC-Extremadura. Social economic costs of chronic obstructive pulmonary disease in Extremadura (Spain): an observational study. Int J Chron Obstruct Pulmon Dis. 2018;13:2501-14.

18. Global Initiative for Chronic Obstructive Lung Disease. Pocket Guide to COPD Diagnosis, Management, and Prevention. In: Global Initiative for Chronic Obstructive Lung Disease; 2017. http://goldcopd.org/wp-content/ uploads/2016/12/wms-GOLD-2017-Pocket-Guide.pdf. Accessed 19 Oct 2017.

19. Garcia-Gordillo MA, Adsuar JC, Olivares PR. Normative values of EQ-5D-5L: in a Spanish representative population sample from Spanish health survey, 2011. Qual Life Res. 2016;25(5):1313-21.

20. EQ-5D-5L UserGuide. EuroQol Research Foundation. 2015. https://eurogol. org/wp-content/uploads/2016/09/EQ-5D-5L_UserGuide_2015.pdf. Accessed 10 Aug 2016.

21. Meguro M, Barley EA, Spencer S, Jones PW. Development and validation of an improved, COPD-specific version of the St. George Respiratory Questionnaire. Chest. 2007;132:456-63.

22. Balcells E, Gimeno-Santos E, de Batlle J, Ramon MA, Rodríguez E, Benet M, et al. Characterisation and prognosis of undiagnosed chronic obstructive pulmonary disease patients at their first hospitalisation. BMC Pulm Med. 2015;15:4.

23. Jones PW, Brusselle G, Negro RWD, Ferrer M, Kardos P, Levy ML, et al. Health-related quality of life in patients by COPD severity within primary care in Europe. Respir Med. 2011;105:57-66.

24. Wacker ME, Jörres RA, Karch A, Wilke S, Heinrich J, Karrasch S, et al. Assessing health-related quality of life in COPD: comparing generic and disease-specific instruments with focus on comorbidities. BMC Pulm Med. 2016;16:70 
25. Burgel PR, Escamilla R, Perez T, Carré P, Caillaud D, Chanez P, et al. Impact of comorbidities on COPD-specific health-related quality of life. Respir Med. 2013;107:233-41.

26. von Leupoldt A, Taube K, Lehmann K, Fritzsche A, Magnussen $H$. The impact of anxiety and depression on outcomes of pulmonary rehabilitation in COPD. Eur Respir J. 2011;38:p3638.

27. Maurer J, Rebbapragada V, Borson S, Goldstein R, Kunik ME, Yohannes AM, et al. Anxiety and depression in COPD. Chest. 2008;134:43S-56S.

28. Miravitlles M, Huerta A, Valle M, García-Sidro P, Forné C, Crespo C, et al. Clinical variables impacting on the estimation of utilities in chronic obstructive pulmonary disease. Int J Chron Obstruct Pulmon Dis. 2015;10: 367-77.

29. Miravitlles M, Huerta A, Fernández-Villar JA, Alcázar B, Villa G, Forné C, et al. Generic utilities in chronic obstructive pulmonary disease patients stratified according to different staging systems. Health Qual Life Outcomes. 2014;12:120.

30. Ministerio de Sanidad y Política Social. Estrategia en EPOC del Sistema Nacional de Salud. In: Sanidad; 2009. http://www.msc.es/organizacion/sns/ planCalidadSNS/docs/EstrategiaEPOCSNS.pdf. Accessed 29 Aug 2016

31. Miravitlles M, Naberan K, Cantoni J, Azpeitia A. Socioeconomic status and health-related quality of life of patients with chronic obstructive pulmonary disease. Respir Int Rev Thorac Dis. 2011;82:402-8.

32. Kurpas D, Szwamel K, Mroczek B. The Environmental Domain of Quality of Life in Patients with Chronic Respiratory Diseases. Adv Exp Med Biol. 2016; 905:5-16.

33. Toledo-Pons N, Cosío BG, Velasco MV, Casanova C. Enfermedad pulmonar obstructiva crónica de origen no tabáquico. Arch Bronconeumol. 2017;53: 45-6.

34. Instituto Nacional de Estadística. España en cifras. 2019. https:/www.ine.es/ prodyser/espa_cifras/2019/20/. Accessed 10 Aug 2019.

\section{Publisher's Note}

Springer Nature remains neutral with regard to jurisdictional claims in published maps and institutional affiliations.

Ready to submit your research? Choose BMC and benefit from:

- fast, convenient online submission

- thorough peer review by experienced researchers in your field

- rapid publication on acceptance

- support for research data, including large and complex data types

- gold Open Access which fosters wider collaboration and increased citations

- maximum visibility for your research: over $100 \mathrm{M}$ website views per year

At $\mathrm{BMC}$, research is always in progress.

Learn more biomedcentral.com/submissions 